\title{
ANALISIS DEBIT PUNCAK SUNGAI LUBUK BANYAU KABUPATEN BENGKULU UTARA DENGAN MENGGUNAKAN METODE HIDROGRAF SATUAN SINTETIK
}

\author{
Agam Sanjaya I $^{\text {() }}$, Khairul AmriII ${ }^{1)}$, Muhammad Fauzi ${ }^{\text {1) }}$ \\ ${ }^{1)}$ Fakultas Teknik Universitas Bengkulu \\ Jl. W. R. Supratman, Kandang Limun, Kota Bengkulu 38371, \\ Corresponding author : agamsnjy2017@yahoo.com
}

\begin{abstract}
Abstrak
Daerah aliran sungai (DAS) Sungai Lubuk banyau merupakan salah satu DAS yang berada di Bengkulu Utara. Penelitian ini bertujuan untuk mengetahui debit puncak rencana akibat intensitas hujan pada DAS Lubuk Banyau. Analisa hidrologi dengan menggunakan metode Hidograf Satuan Sintetik (HSS) Gama I, HSS Nakayasu dan HSS Snyder. hasil perhitungan yang didapat dari penelitian ini distribusi frekuensi terhadap tiga metode curah hujan, yaitu metode ditribusi Gumbel Tipe I, Log Pearson Tipe III dan Log Normal maka metode yang digunakan untuk perhitungan curah hujan rencana pada penelitian ini adalah Metode Gumbel Tipe I dengan periode ulang 2, 5, 10, 25, 50 dan 100 tahun, yaitu 181,164 mm, 275,356 mm, $337,709 \mathrm{~mm}, 416,518 \mathrm{~mm}, 474,974 \mathrm{~mm}$ dan 532,998 mm. Dari hasil analisis hidrologi pada penelitian diperoleh debit puncak pada DAS Lubuk Banyau untuk periode ulang 100 tahun dengan metode HSS Snyder adalah 1531,111 $\mathrm{m}^{3} /$ detik dengan waktu puncak sebesar 5 jam merupakan debit puncak yang paling besar diantara HSS Gama I dan Nakayasu. untuk hasil debit puncak dengan metode HSS Gama I adalah $776,91 \mathrm{~m}^{3} /$ detik dengan waktu puncak sebesar 4 jam dan HSS Nakayasu 1023,87 dengan waktu puncak 2,46 jam. Maka didapatkan tinggi permukaan air pada DAS Lubuk Banyau yaitu 1,134 m.
\end{abstract}

Kata kunci: hidrograf satuan sintetik, debit puncak, gama I, nakayasu, dan snyder

\begin{abstract}
The watershed area (DAS) of the Lubuk Banyau River is one of the watersheds in North Bengkulu. This study aims to determine the planned peak discharge due to rain intensity in the Lubuk Banyau watershed. Hydrological analysis using the Synthetic Unit Hydograph (HSS) method Gama I, HSS Nakayasu and HSS Snyder. The calculation results obtained from this study are the frequency distribution of the three rainfall methods, namely the Gumbel Type I distribution method, the Pearson Type III Log and Normal Log. , 5, 10, 25, 50 and 100 years, namely 181,164 mm, 275,356 mm, 337,709 mm, 416,518 mm, 474,974 mm and 532,998 $\mathrm{mm}$. From the results of the hydrological analysis in the study, it was found that the peak discharge in the Lubuk Banyau watershed for a 100 year return period using the HSS Snyder method was $1531,111 \mathrm{~m} 3$ / second with a peak time of 5 hours which was the biggest peak discharge between HSS Gama I and Nakayasu. for the peak discharge results using the HSS Gama I method is $776.91 \mathrm{~m} 3$ / second with a peak time of 4 hours and HSS Nakayasu 1023.87 with a peak time of 2.46 hours. Then the water level in the Lubuk Banyau watershed was obtained, namely $1.134 \mathrm{~m}$.
\end{abstract}

Keywords:synthetic unit hydrograph, peakdischargegama I, nakayasu, and snyder. 


\section{PENDAHULUAN}

Daerah aliran sungai (DAS) adalah daerah dimana semua airnya mengalir ke dalam suatu sungai yang dimaksudkan. Daerah ini umumnya dibatasi oleh batas topografi, yang berarti ditetapkan berdasarkan pada aliran permukaan, dan bukan ditetapkan berdasarkan pada air bawah tanah karena permukaan air selalu berubah sesuai dengan musim dan tingkat kegiatan pemakaian. (Sri Harto, 1993) dalam (Robot dkk, 2014).

Daerah Sungai Lubuk Banyau merupakan DAS yang berada di Kecamatan Padang Jaya, Bengkulu Utara. Secara geografis letak atau posisi DAS Sungai Lubuk Banyau berada di antara dari 3'21'09.8' Lintang Selatan sampai $102^{\circ} 04^{\prime} 14.5$ " Bujur Timur.

Jembatan Lubuk Banyau yang baru memiliki permasalahan yaitu sampai saat ini belum pernah dilakukan analisis terhadap besaran debit puncak sungai Lubuk Banyau. Sehingga dari pihak Pekerjaan Umum belum menyetujui jembatan yang baru apabila belum adanya pengukuran debit puncak. Hal itu merupakan masalah yang cukup serius dan memerlukan perhatian khusus, agar jembatan bisa digunakan dan tidak tergenang air ketika debit air naik. Jadi, perlu adanya penelitian tentang berapa debit puncak pada sungai Lubuk Banyau menggunakan hidrograf satuan sintetik dalam beberapa periode tahunan. Adapun model hidograf yang digunakan pada penelitian ini adalah model Hidrograf Satuan Sintetik (HSS) Gama I, Hidrograf Satuan Sintetik (HSS) Nakayasu, dan Hidrograf satuan sintetik (HSS) snyder.

\section{TINJAUAN PUSTAKA}

\subsection{Siklus Hidrologi}

Siklus hidrologi adalah gerakan air laut ke udara, kemudian jatuh kepermukaan tanah, dan akhirnya mengalir ke laut kembali (Soemarto, 1999 dalam Anugerah 2016).

\subsection{Daerah Aliran Sungai}

Daerah aliran sungai (DAS) adalah daerah dimana semua airnya mengalir ke dalam suatu sungai yang dimaksudkan. Daerah ini umumnya dibatasi oleh batas topografi, yang berarti ditetapkan berdasarkan pada aliran permukaan, dan bukan ditetapkan berdasarkan pada air bawah tanah karena permukaan air selalu berubah sesuai dengan musim dan tingkat kegiatan pemakaian. (Sri Harto, 1993) dalam (Robot, 2014).

Daerah hulu DAS dicirikan oleh hal-hal sebagai berikut: merupakan daerah konservasi, mempunyai kerapatan drainase lebih tinggi, merupakan daerah dengan kemiringan lereng besar, bukan merupakan daerah banjir. Sementara daerah hilir DAS dicirikan oleh hal-hal sebagai berikut: merupakan daerah pemanfaatan, kerapatan drainase lebih kecil dan merupakan dengan kemiringan lereng kecil. Daerah Aliran Sungai bagian tengah merupakan daerah transisi dari kedua keadaan DAS yang berbeda tersebut (Asdak, 2007 dalam Amri dan Syukron, 2014).

\subsection{Analisis Curah hujan}

Data curah hujan dan debit merupakan data yang paling mendasar dalam perencanaan/penelitian pembuatan bangunan air. Dalam proses pengalihragaman hujan menjadi aliran ada beberapa sifat hujan (I), lama waktu hujan (t), kedalaman hujan (d), frekuensi (f) dan luas daerah pengaruh hujan (Soemarto, 1987 dalam Susilowati dan Kusumastuti, 2010)

\subsubsection{Analisa Hujan Rencana}

Hujan rencana $\left(\mathrm{X}_{\mathrm{T}}\right)$ adalah hujan dengan periode ulang tertentu (T) yang diperkirakan akan terjadi di suatu daerah pengaliran. Periode ulang (T) adalah waktu hipotetik dimana suatu kejadian dengan nilai tertentu, hujan rencana misalnya, akan disamakan atau dilampaui satu kali dalam jangka waktu hipotetik tersebut. Hal ini tidak berarti bahwa hujan rencana akan berulang secara teratur setiap periode ulang tersebut. 
Analisis Debit Puncak Sungai Lubuk Banyau Kabupaten Bengkulu Utara dengan Menggunakan Metode Hidrograf Satuan Sintetik

\subsubsection{Rata-Rata Curah Hujan sebagai Dasar Curah Hujan di DAS}

Metode Aritmatik hujan ditentukan dengan cara menjumlahkan tinggi hujan dari semua tempat pengukuran selama periode tertentu, dibagi dengan jumlah pos pengukuran (Gambar 2.2). Berikut persamaan Metode Aritmatik (SNI 2415:2016, hlm. 64) $\overline{\mathrm{P}}=\frac{\mathrm{P} 1+\mathrm{P} 2+\cdots+\mathrm{Pn}}{\mathrm{n}}$

\subsubsection{Distribusi Probabilitas Kontinu}

Perolehan besar hujan rencana dalam analisis frekuensi dikenal beberapa distribusi probabilitas kontinu yang sering digunakan, yaitu Distribusi Gumbel Tipe I, Distribusi Normal, Distribusi Log Normal, dan Distribusi Log Pearson Tipe III.

\section{a. Metode Distribusi Gumbel Tipe I}

Distribusi Gumbel Tipe I atau disebut juga dengan distribusi ekstrem tipe I (extreme type I distribution) umumnya digunakan untuk analisis data maksimum, misal untuk frekuensi banjir (Soewarno,1995).

\section{b. Metode Distribusi Normal}

- Prosedur perhitungan dengan Metode Distribusi Normal (SNI 2415:2016,) adalah sebagai berikut :

1. Kumpulkan data maksimum $<20$ tahun;

2. Hitung parameter statistik (Rata-rata $(\overline{\mathrm{X}})$, Standar Deviasi $\left(\mathrm{S}_{\mathrm{d}}\right), \quad$ Koefisien Kemencengan/Skewness $\left(\mathrm{C}_{\mathrm{s}}\right), \quad$ dan Koefisien Kurtosis $\left(\mathrm{C}_{\mathrm{k}}\right)$.

3. Periksa apakah $\mathrm{C}_{\mathrm{s}} \approx 0$ dan $\mathrm{C}_{\mathrm{k}} \approx 3$. Jika ya maka dapat menggunakan formula Distribusi Normal, jika tidak maka pilih metode distribusi lainnya.

4. Jika $\mathrm{C}_{\mathrm{s}} \approx 0$ dan $\mathrm{C}_{\mathrm{k}} \approx 3$, hitung besar curah hujan rencana $\left(\mathrm{X}_{\mathrm{Tr}}\right)$ berdasarkan persamaan-persamaan pada Metode Distribusi Normal.

\section{c. Metode Distribusi Log Normal}

Prosedur perhitungan dengan Metode Distribusi Log Normal (SNI 2415:2016, hlm.

13) adalah sebagai berikut :

1. Kumpulkan data maksimum $>20$ tahun;

2. Data dilogkan $(\log X 1, \log X 2, \log X 3$, dst);
3. Hitung parameter statistik dengan menggunakan data dari langkah kedua (Rata-rata $(\overline{\mathrm{X}})$, Standar Deviasi $\left(\mathrm{S}_{\mathrm{d}}\right)$, Koefisien Kemencengan/Skewness $\left(\mathrm{C}_{\mathrm{s}}\right)$, dan Koefisien Kurtosis $\left(\mathrm{C}_{\mathrm{k}}\right)$.

4. Periksa apakah $\mathrm{C}_{\mathrm{s}} \approx 3$ positif atau tiga kali koefisien variasi $\left(\mathrm{C}_{\mathrm{v}}\right)$. Jika ya maka dapat menggunakan formula Distribusi Log Normal, jika tidak maka pilih metode distribusi lainnya.

5. Jika $\mathrm{C}_{\mathrm{s}} \approx 3$ positif atau tiga kali koefisien variasi $\left(\mathrm{C}_{\mathrm{v}}\right)$, hitung besar curah hujan rencana $\left(\mathrm{X}_{\mathrm{Tr}}\right)$ berdasarkan persamaanpersamaan pada Metode Distribusi Log Normal.

\section{d. Metode Distribusi Log Person Tipe III}

Prosedur perhitungan dengan Metode Distribusi Log Normal (SNI 2415:2016) adalah sebagai berikut :

1. Kumpulkan data maksimum $>20$ tahun;

2. Data dilogkan $(\log X 1, \log X 2, \log X 3$, ...... dst);

3. Hitung parameter statistik dengan menggunakan data dari langkah kedua (Rata-rata $(\overline{\mathrm{X}})$, Standar Deviasi $\left(\mathrm{S}_{\mathrm{d}}\right)$, Koefisien Kemencengan/Skewness $\left(\mathrm{C}_{\mathrm{s}}\right)$, dan Koefisien Kurtosis $\left(\mathrm{C}_{\mathrm{k}}\right)$.

4. Periksa apakah Koefisien Kemencengan/Skewness $\left(\mathrm{C}_{\mathrm{s}}\right)$ dan Koefisien Kurtosis $\left(\mathrm{C}_{\mathrm{k}}\right)$ tidak memenuhi syarat distribusi Gumbel Tipe I, Normal, dan Log Normal. Jika ya maka dapat menggunakan formula Distribusi Log Pearson Tipe III.

\subsubsection{Pengujian Distribusi Probabilitas}

\section{(Goodness of Fit)}

Uji distribusi probabilitas dimaksudkan untuk mengetahui apakah persamaan distribusi probabilitas yang dipilih dapat mewakili distribusi statistik sampel data yang dianalisis (Kamiana, 2011).

\subsubsection{Analisis Frekuensi}

Secara sistematis metode analisis frekuensi perhitungan hujan rencana ini dilakukan secara berurutan yaitu, parameter 
statistik, distribusi probabilitas kontinyu, dan pengujian kecocokan sebaran.

\subsubsection{Analisis Intensitas Curah Hujan}

Analisis intensitas curah hujan ini dapat diproses dari data curah hujan yang telah terjadi pada masa lampau. Dengan tersedianya data curah hujan harian, perhitungan curah hujan rencana dapat dilakukan dengan menggunakan rumus empiris dari Mononobe sebagai berikut :

$$
I=\frac{R_{24}}{t_{c}} \times\left[\frac{t_{c}}{t}\right]^{2 / 3}
$$

\subsubsection{Penentuan Waktu Konsentrasi}

Salah satu metode untuk memperkirakan waktu konsentrasi adalah dengan rumus yang dikembangkan oleh Kirpich (1940) dalam (Sriyono, 2012), yaitu:

$$
t_{c}=0,06628 \times L^{0,77} \times S^{-0,385}
$$

\subsubsection{Analisis Debit Banjir Rencana}

Untuk menganalisa debit banjir rencana dapat dilakukan dengan menggunakan metode hidrograf yang dilakukan dengan menggunakan bantuan model hidrograf satuan sintetik dan model non hidrograf yang dilakukan dengan teknik analisa frekuensi

\section{a) Kriteria Perencanaan Penentuan \\ Periode Ulang Banjir}

Berbagai macam bangunan-bangunan air memerlukan perhitungan hidrologi yang merupakan bagian dari perencanaan bangunan-bangunan tersebut. Pemilihan periode ulang (retrun period) banjir rencana untuk bangunan air adalah suatu masalah yang sangat bergantung pada analisa statistik dari urutan kejadian banjir baik berupa debit air di sungai maupun curah hujan badai.

\section{b) Aliran Dasar (Base Flow)}

Hidrograf aliran langsung dapat diperoleh dengan memisahkan hidrograf dari aliran dasarnya. Ada beberapa cara yang dapat dilakukan, diantaranya adalah metode garis lurus (straight line method), metode panjang dasar tetap (fixed base method) dan metode kemiringan berbeda (variable slope methode)

\section{Metode Hidrograf Satuan Sintetik Gama I}

Hidrograf satuan sintetik Gama I dikembangkan oleh Sri Harto berdasar perilaku hidrologi 30 DAS di Pulau Jawa. Meskipun diturunkan dari data DAS di Pulau Jawa, ternyata hidrograf satuan sintetik Gama I juga berfungsi baik untuk berbagai daerah lain di Indonesia .

c) Metode Hidrograf Satuan Sintetik Nakayasu

Hidrograf Satuan Sintetik (HSS) Nakayasu merupakan suatu cara untuk mendapatkan hidrograf banjir rencana dalam suatu DAS. Untuk membuat suatu hidrograf banjir pada sungai, perlu dicari karakteristik atau parameter daerah pengaliran tersebut. Adapun karakteristik tersebut adalah (Sutapa, 2005):

1) Tenggang waktu dari permulaan hujan sampai puncak hidrograf (time to peak magnitute).

2) Tenggang waktu dari titik berat hujan sampai titik berat hidrograf (time log).

3) Tenggang waktu hidrograf (time base of hydrograf).

4) Luas daerah pengaliran.

Panjang alur sungai utama (lenght of the longest channel).

d) Metode Hidrograf Satuan Sintetik Snyder

Snyder mengembangkan rumus dengan koefisien - koefisien empirik yang menghubungkan unsur - unsur hidrograf satuan dengan karakteristik daerah pengaliran dan menganalisa sejumlah hidrograf DAS di Appalchian Mountain Region (USA) dengan Luas DAS $\left(25 \mathrm{~km}^{2}-25.000 \mathrm{~km}^{2}\right)$.

\section{METODE PENELITIAN}

\section{Lokasi penelitian}

Daerah Sungai Lubuk Banyau merupakan DAS yang berada di Kecamatan Padang Jaya, Bengkulu Utara. Letak atau posisi DAS Sungai Lubuk Banyau secara geografis 
Analisis Debit Puncak Sungai Lubuk Banyau Kabupaten Bengkulu Utara dengan Menggunakan Metode Hidrograf Satuan Sintetik

berada di antara dari $3^{\circ} 21^{\prime} 09.8^{\prime \prime}$ Lintang Selatan sampai $102^{\circ} 04^{\prime} 14.5$ ' Bujur Timur.

\section{Pengumpulan Data}

Data yang digunakan adalah Data Primer dan Data Sekunder

a. Data Primer

Pengumpulan data primer dilakukan langsung dilapangan. Pengumpulan data primer menggunakan metode survey. Data Primer yang digunakan dalam penelitian ini yaitu :

1. Luas Penampang

Pengukuran luas penampang dilakukan langsung dilapangan sesuai dengan SNI 2088:2015 tentang Tata cara pengukuran debit aliran sungai dan saluran terbuka menggunakan alat ukur arus dan pelampung. Adapun alat yang digunakan dalam pengukuran adalah meteran dan bambu.

2. Kecepatan Aliran

Pengukuran kecepatan aliran menggunakan currentmeter menggunakan acuan SNI 8066:2015 tentang tata cara pengukuran debit aliran sungai dan saluran terbuka menggunakan alat ukur arus dan pelampung.

3. Tahapan pengukuran dengan menggunakan currentmeter

Data debit aliran diperoleh dari hasil kecepatan aliran dikalikan dengan luas penampang.

Data sekunder yang digunakan dalam penelitian ini antara lain:

a) Peta DAS dan Peta topografi DAS Sungai Bengkulu didapatdari BWS Sumatera VII.

b) Data curah hujan selama 10 tahun terakhir (2007-2017) beserta stasiun hujan yang ada didalamnya didapat dari BMKG Provinsi Bengkulu.

\section{Alat Penelitian}

Peralatan yang digunakan pada penelitian ini diantaranya:

a) Alat tulis digunakan untuk mencatat hasil pengukuran. b) Roll meter yang digunakan sebagai alat pengukur di lapangan.

c) Current meteryang digunakan untuk menghitung kecepatan aliran sungai.

d) Peilshaal yang digunakan untuk mengukur kedalaman dalam penampang basah sungai.

e) Stopwatchdigunakan untuk mengukur lamanya waktu yang diperlukan.

f) Kalkulator digunakan perhitungan data.

g) Komputer digunakan untuk mengolah data.

\section{Perhitungan Debit Puncak}

Tahapan pelaksanaan penelitian yang akan dilakukan adalah sebagai berikut:

a. Analisis curah hujan harian

Analisa curah hujan harian dihitung dengan menggunakan data curah hujan yang diperoleh dari BWSS VII Bengkulu yang dibagi oleh 2 pos stasiun yaitu Pos Kemumu dan Pos Air Lais yang ada di dalam kawasan DAS Lubuk Banyau. Perhitungan analisis curah hujan harian menggunakan cara partial series (PS) yaitu mengurutkan data curah hujan dari kecil ke besar setelah diperoleh maksimum di tiap tahunnya.

b. Analisis curah hujan rencana

Analisis curah hujan rencana untuk mengetahui besaran peristiwa ekstrim yang berkaitan dengan frekuensi kejadiannya melalui penerapan distribusi kemungkinan. Perhitungan ini menentukan parameter statistik dari data yang telah diurutkan. Selanjutnya, menganalisis besar curah hujan rencana yang harus memenuhi beberapa parameter yang menjadi syarat penggunaan metode distribusi. Metode distribusi yang digunakan adalah distribusi gumbel tipe I, distribusi log pearson tipe III dan distribusi normal. Pengujian kecocokan sebaran digunakan uji kecocokan sebaran ChiKuadrat (chi-square) dan uji kecocokan sminov kolmogorov.

c. Analisis Debit Banjir rencana

Perhitungan debit rencana diperlukan untuk perencanaan pengendalian banjir. Pada 
penelitian ini metode penentuan debit banjir rencana akan dilakukan dengan metode hidrograf satuan sintetik gamal, nakayasu dansnyder.Penelitian ini menghitung debit puncak rencana dengan periode ulang 2 tahun, 5 tahun, 10 tahun, 20 tahun, 25 tahun, 50 tahun dan 100 tahun.

\section{Hasil dan Pembahasan}

Dari hasil rekapitulasi hidrograf banjir rencana pada Tabel 1 dari periode ulang 2 tahun sampai 100 tahun, dibuat grafik hidrograf banjir untuk DAS Lubuk Banyau dilihat pada Gambar 1, 2 dan 3

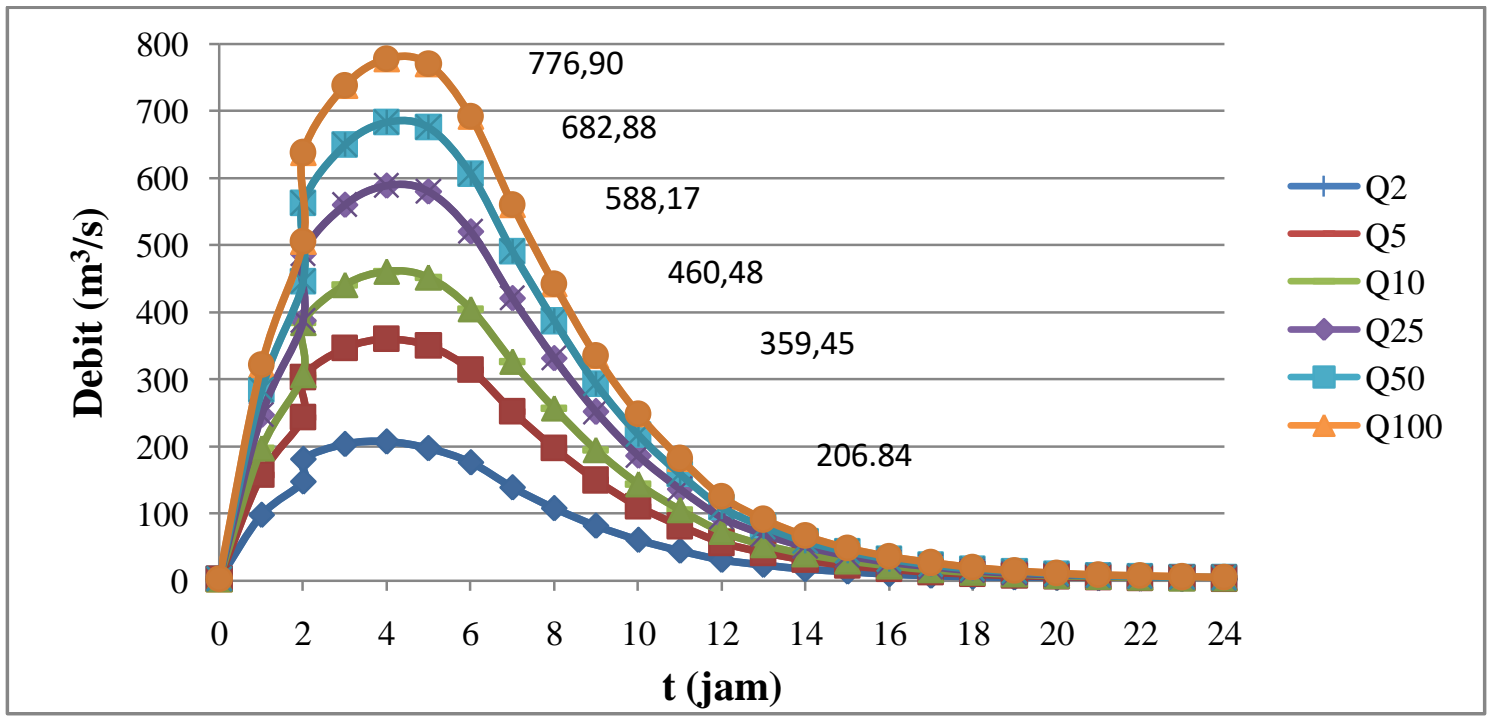

Sumber : HasilPerhitungan, 2019

Gambar 1. Hidrograf Banjir Gama I
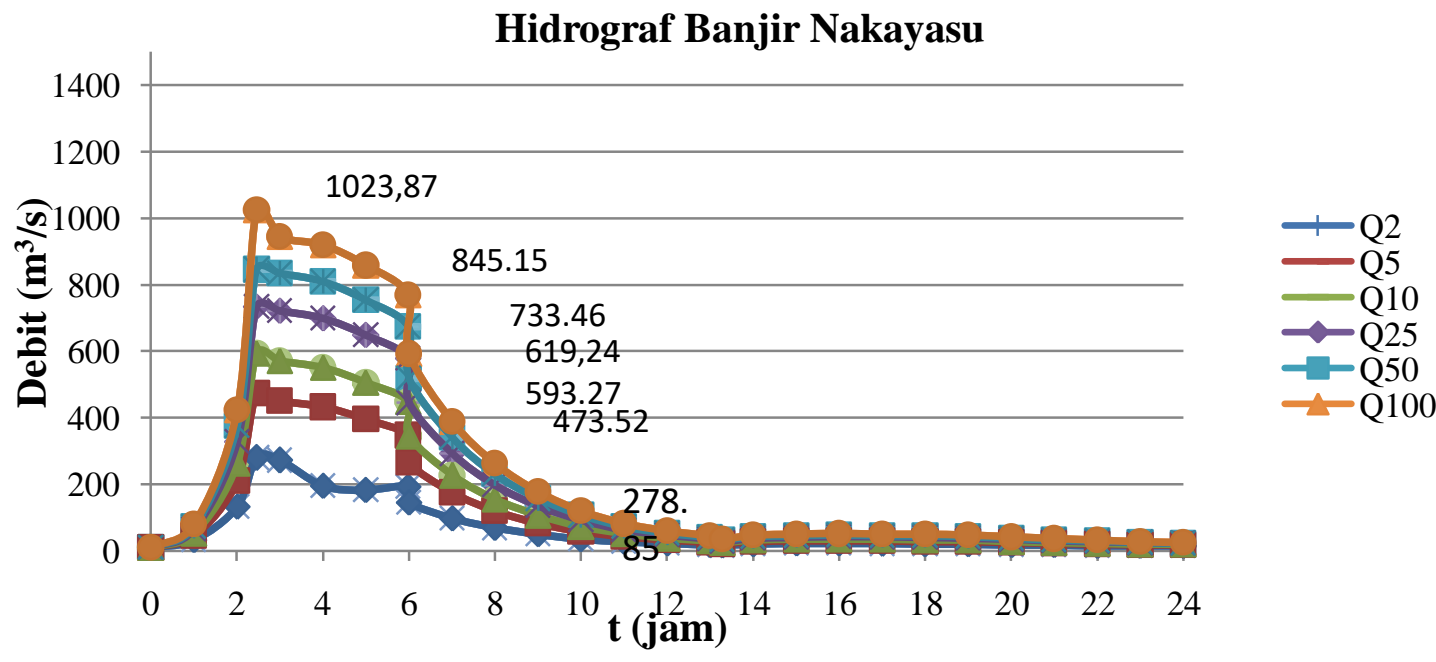

Sumber :HasilPerhitungan, 2019

Gambar 2. Hidrograf BanjirNakayasu 


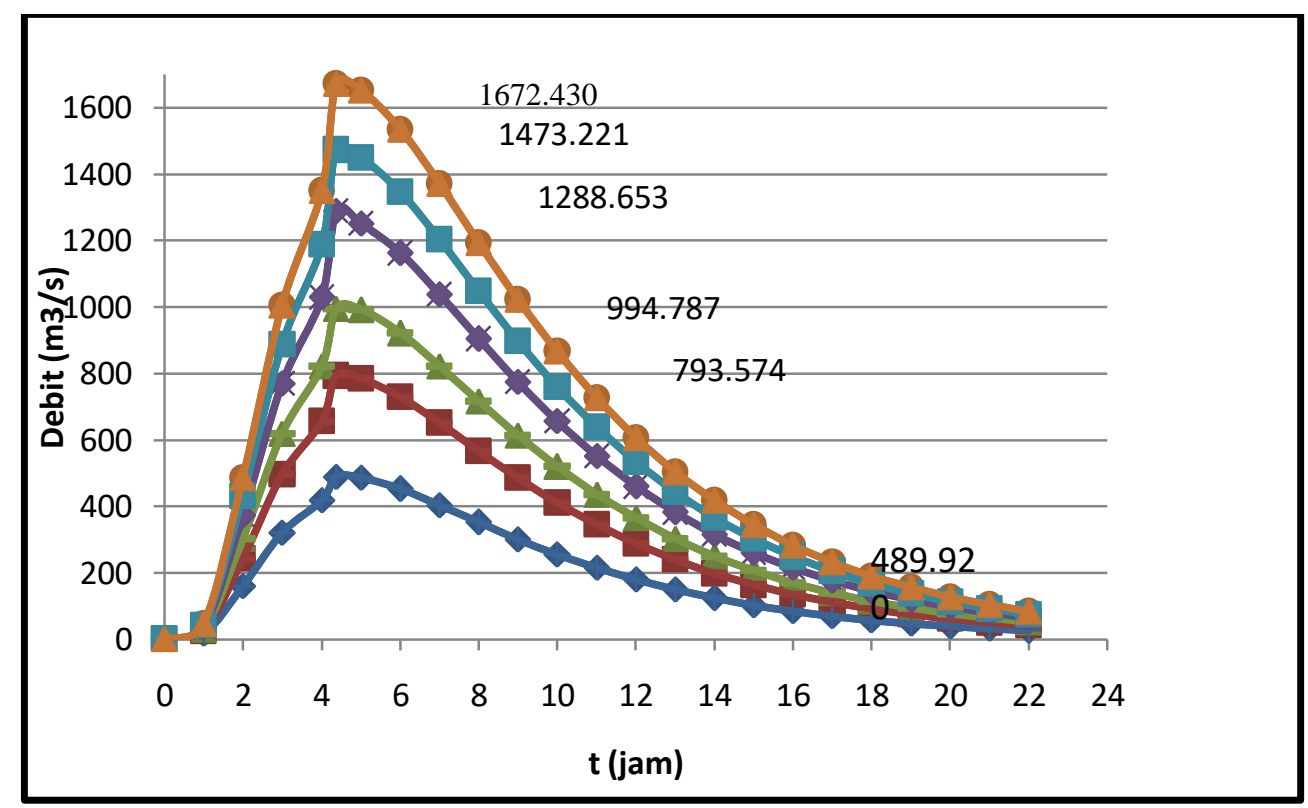

Sumber :HasilPerhitungan, 2019

Gambar 3. Hidrograf Debit Banjir Snyder

Tabel 1. Hasil Berdasarkan Rekapitulasi Perhitungan Debit Rencana.

\begin{tabular}{|c|c|c|c|c|}
\hline \multirow{2}{*}{ No } & \multirow{2}{*}{ Periode Ulang } & \multicolumn{3}{|c|}{ Debit Banjir Rencana $\left(\mathrm{m}^{3} /\right.$ detik) } \\
\cline { 3 - 5 } & & HSS Gama I & HSS Nakayasu & HSS Snyder \\
\hline 1 & 2 & 206,83 & 278,85 & 489,920 \\
\hline 2 & 5 & 359,45 & 473,52 & 793,574 \\
\hline 3 & 10 & 460.48 & 593,27 & 994,787 \\
\hline 4 & 25 & 588.17 & 733,46 & 1288,653 \\
\hline 5 & 50 & 682.88 & 845,15 & 1473,221 \\
\hline 6 & 100 & 776.90 & 1023,86 & 1672,430 \\
\hline
\end{tabular}

Sumber:HasilPerhitungan, 2019

\section{KESIMPULAN}

Kesimpulan yang dapat ditarik oleh penulis berdasarkan hasil dan pembahasan adalah sebagai berikut:

1. Debit puncak yang didapat DAS Lubuk Banyau untuk periode ulang 100 tahun dengan metode HSS Gama 1 yaitu 776,90 m3/detik dengan waktu puncak 4 jam. Hasil debit puncak dengan HSS Nakayasu yaitu 1023,86 m3/detik dengan waktu puncak 2,46 jam. Hasil debit puncak dengan HSS Snyder yaitu 1672,430 dengan waktu puncak 4,337.

2. Dari ketiga metode ini, metode HSS Snyder lebih sesuai kondisi lapangan dan hasil lebih tinggi dari HSS Gama 1 dan HSS Nakayasu, maka didapat tinggi muka air pada Lubuk Banyau 1,047 m dari dasar sungai, sedangkan tinggi elevasi jembatan yaitu $11 \mathrm{~m}$. Jadi, jembatan yang baru layak digunakan sebagaimana fungsinya.

\section{DAFTAR PUSTAKA}

Amri, K, dan Syukron, 2014. Analisis Debit Puncak DAS Padang Guci Kabupaten Kaur Provinsi Bengkulu. Universitas Bengkulu, 
Anugerah A. J, Isri R, Mangangka, dan E. M. Wuisan, 2016. Analisa Debit Banjir Sungai Ranoyapo Di desa Lindangan, Kec Tompaso Baru, Kab. Minahasa Selatan. Fakultas Teknik, Universitas Sam Ratulangi Manado,

Kamiana, 2011. Pengujian Distribusi Probabilitas

Robot AJ, Mananoma, Wuisan, dan Tangkudung 2014. Analisis Debit Banjir Sungai Ranoyapo Menggunakan Metode HSS Gama-1 Dan HSS Limantara. Fakultas Teknik, Universitas Sam Ratulangi Manado, Volume 2, No 1, Tahun.

SNI 8066. 2015. Tata cara pengukuran debit aliran sungaidan saluran terbuka menggunakanalat ukur arus dan pelampung.Badan Standardisasi Nasional. ICS 93.025. 4-10

SNI 2088:2015 tentang Tata cara pengukuran debit aliran sungai

SNI 2415:2016, Metode Aritmatik

Sriyono, E., 2012. Analisis Debit Banjir Rancangan Rehabilitas Situ Sidomukti, Fakultas Teknik Universitas Janabadra. Yogyakarta,

Susilowati, dan Kusumastuti, 2010. Analisa Karakterisistik Curah Hujan Dan Kurva Intensitas Hujan Frekuensi (IDF) Di Provinsi Lampung. Triatmodjo, B., 2008.Hidrologi Terapan, Beta Offset, Yogyakarta.

Sutapa, I. W., 2005. Kajian Hidrograf Satuan Sintetik Nakayasu Untuk Perhitungan Debit Banjir Rancangan Di Daerah Aliran Sungai Kodina. Fakultas Teknik Universitas Tadulako, Palu, Tahun VII, No.1, Januari 2005. 